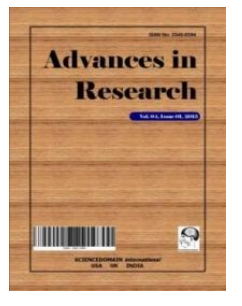

\title{
Advances in Research
}

9(6): 1-8, 2017; Article no.AIR.33213

ISSN: 2348-0394, NLM ID: 101666096

\section{Analysis of Lead-210 in Surface Water nearby a Phosphate Mining at Semi-arid Region in Santa Quitéria, Ceará State, Brazil}

\author{
Wagner de Souza Pereira ${ }^{1,2^{*}}$, Alphonse Kelecom ${ }^{3}$, \\ Marcos Vivente Bento Macedo ${ }^{1}$, Rosane Santos Araujo ${ }^{1}$, \\ Júlia Martinelli Fabbri ${ }^{1}$ and Dulcinea Silva Gomes Santos ${ }^{1}$ \\ ${ }^{1}$ Universidade Veiga de Almeida, Rua Ibituruna, 108, Tijuca, R.J. 20.271-020, Brazil. \\ ${ }^{2}$ Indústrias Nucleares do Brasil, Rod. Pr. Dutra km 330, 27.555-000, Resende, Brazil. \\ ${ }^{3}$ Universidade Federal Fluminense - UFF, C.P. 100436, CEP 24.001-970, Niterói, RJ, Brazil.
}

Authors' contributions

This work was carried out in collaboration between all authors. Author WSP designed the study, managed the analyses of the study, wrote the protocol, draft and final version. Author AK wrote the

protocol and the first draft of the manuscript, final and english version. Authors MVBM and RSA performed sampling collections, chemistry analysis and statistical analysis. Authors JMF and DSGS managed the literature searches, samples collections and chemistry analysis. All authors read and approved the final manuscript.

Article Information

DOI: $10.9734 / \mathrm{AIR} / 2017 / 33213$ Editor(s):

(1) S. Srinivasa Rao, Department of Chemistry, V. R. Siddhartha Engineering College, Andhra Pradesh, India. Reviewers:

(1) Suheyla Yerel Kandemir, Bilecik Seyh Edebali University, Turkey (2) Caroline Lomalungelo Dlamini, College of Science, University of South Africa (UNISA), South Africa. (3) Tatiana Hrušková, Universtity of Veterinary Medicine and Pharmacy, Košice, Slovakia. (4) Ronald Bartzatt, University of Nebraska at Omaha, USA. (5) Enedina Jiménez Cardoso, Children Hospital of Mexico, Mexico. Complete Peer review History: http://www.sciencedomain.org/review-history/19243

Original Research Article

Received $4^{\text {th }}$ April 2017

Accepted 27 ${ }^{\text {th }}$ May 2017

Published $30^{\text {th }}$ May 2017

ABSTRACT

Aims: To report the activity concentrations $(\mathrm{AC})$ of ${ }^{210} \mathrm{~Pb}$ in surface waters in a semi-arid region, aiming to record these concentrations before the beginning of a Naturally Occurring Radioactive Material (NORM) mining operation, facilitating subsequent comparisons with the operational phase besides verifying the radioecological characteristics of this radionuclide and the potability of the water used for human consumption by the local population. 
Study Design: The water samples were collected in a six points grid associated to places of human consumption, aiming to verify their radioecological characteristics and radiological potability. Place and Duration of Study: The study site was a semi-arid region associated to a NORM phosphate deposit, between October 2009 and December 2011. No collection occurred in January and February 2010, accounting for 25 collections and 50 analyzes (soluble and particulate) per point.

Methodology: $1 \mathrm{~L}$ of water, per point, was collected acidulated and filtered. The filtrate was considered as the soluble fraction and the retained part as the particulate fraction. The ${ }^{210} \mathrm{~Pb}$ was separated by coprecipitation and analyzed by total beta counts. Data were analyzed by univariate and multivariate statistical methods and the values found were compared with international potability standards.

Results: The values found were within the international recommendations of ingestion of ${ }^{210} \mathrm{~Pb}$ in water (mean value of $0.05 \mathrm{~Bq} \cdot l^{-1}<$ recommended of $0.1 \mathrm{~Bq} \cdot l^{-1}$ ). Radionuclide radioecology proved to be complex. The total $\mathrm{AC}$ of ${ }^{210} \mathrm{~Pb}$ (sum of the soluble and particulate fractions) showed no difference between points, ranging from $0.05 \mathrm{~Bq} \cdot \mathrm{l}^{-1}$ at point $01 \mathrm{SQ}$ to $0.10 \mathrm{~Bq} \cdot \mathrm{l}^{-1}$ at point $04 \mathrm{SQ}$. But when the $A C$ of the fractions were analyzed, it could be verified that the $A C$ of the particulate fraction were systematically higher than that of the soluble fraction.

Conclusion: The analyzed water, in relation to the activity concentration of ${ }^{210} \mathrm{~Pb}$, is considered potable and the particulate fraction has higher AC than the soluble fraction. The characterization of the water must be complemented when entering the operation of the phosphate mine to verify the radiological environmental impact assessment of the enterprise.

Keywords: Pb-210; Santa Quitéria; NORM; phosphate mining; individual dose criterion; water potability.

\section{INTRODUCTION}

Mining of minerals associated with uranium, known as Naturally Occurring Radioactive Material (NORM), exposes the local population and biota to increased radiation exposure. Mining of phosphate [1], titanium [2], rare earths and thorium [3], zirconium and zirconia [4], and cassiterite [5] among others are recognized as causing increased exposure.

Brazil has the world's sixth largest uranium reserves [6]. From the mid-1980s until the mid1990s, these reserves were mined at the "Osamu Utsami" mine in the city of Caldas, state of Minas Gerais. From the beginning of the 2000s the exploration is being carried out in the waterfall mine known as "Cachoeira", in the city of Caetité, state of Bahia. Aiming at the continuation of uranium exploration, the next deposit in conditions of economic, technical and environmental feasibility is "Jazida Itataia", a phosphate deposit with associated uranium, in the City of Santa Quiterria, state of Ceará [7].

The latter mine, in phase of implantation, possesses phosphate reserves estimated at nine million tons of $\mathrm{P}_{2} \mathrm{O}_{5}$ with associated uranium estimated in 79,500 tons of $U_{3} \mathrm{O}_{8}$ [8]. It is located in a rather particular ecotone, an ecological transition zone between savanna and cerrado, two Brazilian ecosystems threatened with extinction [9].

One of the possible impacts of phosphate extraction may be the contamination of surface waters with phosphate, heavy metals and radionuclides. In semi-arid regions water management in quantity and quality (potability) is a vital variable for the local population that uses this resource without any treatment. This area has previously been studied, by Pereira et al. [9] focusing on the radioecology of radium (both ${ }^{226} \mathrm{Ra}$ and ${ }^{228} \mathrm{Ra}$ isotopes) in surface waters.

Following Brazilian law [10-13], areas with ore reserves associated with uranium and thorium needs to be accompanied by a radioecology evaluation and of a radiological environmental impact assessment (REIA) based on an environmental radiological monitoring program.

This study aims to evaluate the activity concentrations (AC) of ${ }^{210} \mathrm{~Pb}$ in surface waters of the Santa Quitéria region, using statistical analytical tools with univariate and multivariate approaches and the potability of water view from the radiological point. 


\section{MATERIALS AND METHODS}

\subsection{Study Area}

The study area is situated in the municipality of Santa Quitéria, state of Ceará, Brazilian semiarid northeast, in the surroundings of the phosphate deposit with associated uranium and thorium (Fig. 1).

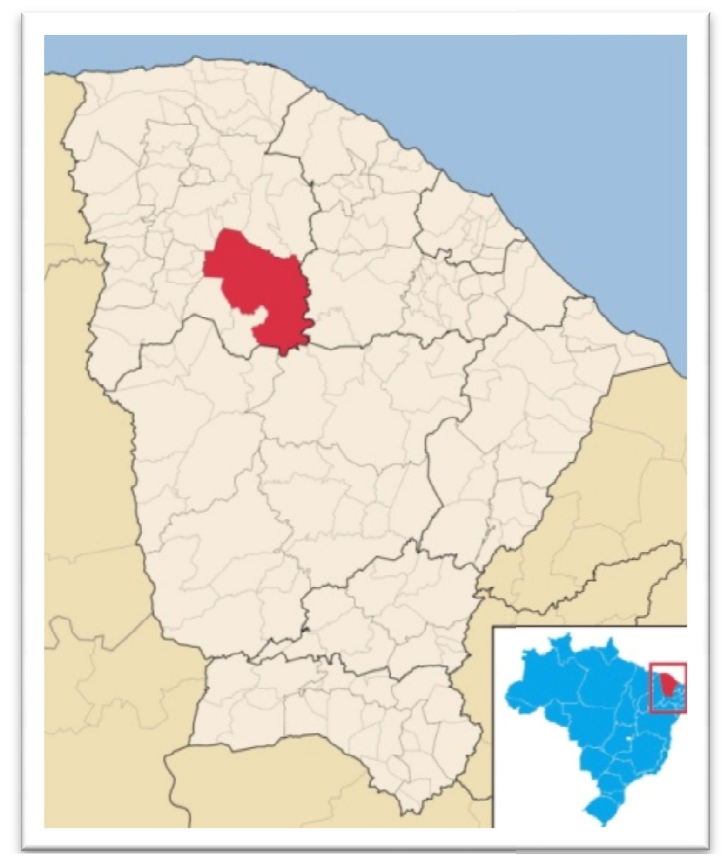

Fig. 1. Location of Santa Quitéria municipality in the state of Ceará, Brazil (Adapted from Wikipedia)

\subsection{Sample Collection and Preparation}

The water samples were collected at six different points, (01SQ to 06SQ) as given in Table 1. One liter of surface water was collected at each point every month over a period of 25 months. They were acidified with $1 \mathrm{ml}$ conc. $\mathrm{HNO}_{3}$, and then filtered on an acetate filter with porosity $0.45 \mu \mathrm{m}$. The filtrate was considered the soluble fraction and the material retained onto the filter was considered the particulate fraction.

Table 1. Geographical locations of water collecting points in "UTM" coordinates

\begin{tabular}{lll}
\hline Points & UTM E & UTM N \\
\hline 01SQ & 0408575 & 9495305 \\
02SQ & 0409766 & 9496141 \\
03SQ & 0415241 & 9496141 \\
04SQ & 0413784 & 9493155 \\
05SQ & 0410362 & 9494800 \\
06SQ & 0411850 & 9494292 \\
\hline
\end{tabular}

\subsection{Determination of ${ }^{210} \mathrm{~Pb}$}

${ }^{210} \mathrm{~Pb}$ was concentrated from water by selective coprecipitation. The precipitate was collected on a filter and then submitted to gross beta counting in a proportional counter, following Godoy et al. [14].

\subsection{Sample Design and Data Organization}

Data were arranged in a matrix, where the columns represent the combination of collecting points and fractions, and the rows the collection dates, creating a data matrix of $12 \times 25$ containing the 300 values of ${ }^{210} \mathrm{~Pb}$ activity concentration analyzed for the sampled area.

\subsection{Univariate Statistical Analysis}

A descriptive statistics of data was performed that furnished the mean values, standard deviation, maximum value, and the number of samples. After that, a one-tailed $Z$ test was carried out to compare the means of activity concentration between the soluble and particulate fractions [15]. Tested hypotheses were:

$$
\begin{aligned}
H_{0}= & \text { The means of the fractions are } \\
\text { statistically identical } & \\
H_{1}= & \begin{array}{l}
\text { The means of the fractions are } \\
\text { statistically different }
\end{array}
\end{aligned}
$$

Then two analyses of variance (ANOVA) were performed in the data matrix to identify the relationship between the average per point in total fraction and per point in soluble and particulate fraction [15], following the hypotheses:

$$
\begin{aligned}
& H_{0}=\text { All the means are statistically identical } \\
& H_{1}=\text { There is at least one mean different }
\end{aligned}
$$

Observing a difference, the Fisher's test was performed for classifying means [15-17].

\subsection{Multivariate Statistical Analysis}

\subsubsection{Principal component analysis}

The evaluation of multiple data is always difficult to perform for different reasons. One way to solve these problems is the use of multivariate analysis techniques. Among such techniques, the Principal Component Analysis (PCA) is the most used. This technique employs a matrix arrangement of data and generates from this array a pair of orthogonal axes, where the data 
are organized in function of parameters (factors) related on the variance of the data [18-19].

\subsubsection{Cluster analysis}

This analysis presents multiple data in groups based on data similarities and differences [18-19].

\section{RESULTS AND DISCUSSION}

\subsection{Univariate Statistical Analysis}

In the particulate fraction, the ${ }^{210} \mathrm{~Pb}$ activity concentrations ranged from $0.0442 \mathrm{~Bq} \cdot \mathrm{l}^{-1}$ at point 03SQ to $0.0292 \mathrm{~Bq} \cdot \cdot^{-1}$ at point $05 S Q$, while in the soluble fraction, the highest activity concentration was observed for the same point (05SQ) with the same value $0.0292 \mathrm{~Bq} \cdot \mathrm{I}^{-1}$. Instead, the lowest activity concentration of the soluble fraction appeared at point 04SQ $\left(0.0099 \mathrm{Bql}^{-1}\right)$. For the total fraction, the value ranged from 0.05 to 0.10 $\mathrm{Bq} \cdot \mathrm{I}^{-1}$ at points 01SQ and 04SQ. Descriptive statistics is presented in Table 2, Fig. 2 for soluble and particulate fraction and Fig. 3 for total fraction.

The $\mathrm{Z}$ test between all data from soluble and particulate fractions, regardless of the sampling point, with a $Z$ value of 2.01 associated with a $P$ value of 0.02 , indicated $\mathrm{H}_{0}$ as the rejected hypothesis, suggesting differences between the fractions. Thus, the mean activity concentration of the particulate fraction $\left(0.0334 \mathrm{~Bq} \cdot \mathrm{I}^{-1}\right)$ was considered the highest as that of the soluble fraction $\left(\left.0.0191 \mathrm{~Bq} \cdot\right|^{-1}\right)$.

A different conclusion occurred from the analysis of variance of the total fractions. With $F_{\text {cal }}$ equal to $0.29(P=0.92) \mathrm{H}_{0}$ is accepted, suggesting equality between the $\mathrm{AC}$ of points. In this case, there are no points with different $A C$.

The ANOVA for fractions resulted in a different frame. In this case the calculated value of $F\left(F_{\text {cal }}\right)$ was 1.33 , with an associated $P$ value of 0.021 . Thus, $\mathrm{H}_{0}$ was rejected, suggesting differences between the AC of fraction and point. A Fisher's test was thus carried out.

Table 2. Descriptive statistics of $\mathrm{AC}$, for ${ }^{210} \mathrm{~Pb}$ in surface waters in the region of Santa Quiteria $\left(\mathrm{Bq} \cdot \cdot^{-1}\right)$

\begin{tabular}{llllllll}
\hline \multirow{2}{*}{ Point } & \multicolumn{2}{c}{ Soluble fraction } & \multicolumn{2}{c}{ Particulate fraction } & \multicolumn{2}{c}{ Total fraction } & N \\
\cline { 2 - 6 } & Mean \pm st. dev. & Max. & Mean \pm st. dev. & Max. & Mean \pm st. dev. & Max. & \\
\hline 01SQ & $0.013 \pm 0.011$ & 0.041 & $0.035 \pm 0.031$ & 0.118 & $0,051 \pm 0,040$ & 0,159 & 25 \\
O2SQ & $0.012 \pm 0.011$ & 0.037 & $0.032 \pm 0.031$ & 1.318 & $0,093 \pm 0,256$ & 1,318 & 25 \\
03SQ & $0.020 \pm 0.023$ & 0.096 & $0.044 \pm 0.040$ & 0.167 & $0.080 \pm 0.081$ & 0.395 & 25 \\
04SQ & $0.010 \pm 0.008$ & 0.032 & $0.034 \pm 0.033$ & 0.114 & $0.097 \pm 0.244$ & 1.244 & 25 \\
05SQ & $0.029 \pm 0.033$ & 0.118 & $0.029 \pm 0.028$ & 0.104 & $0.076 \pm 0.115$ & 0.593 & 25 \\
06SQ & $0.019 \pm 0.017$ & 0.061 & $0.032 \pm 0.031$ & 0.107 & $0.067 \pm 0.069$ & 0.277 & 25 \\
\hline
\end{tabular}

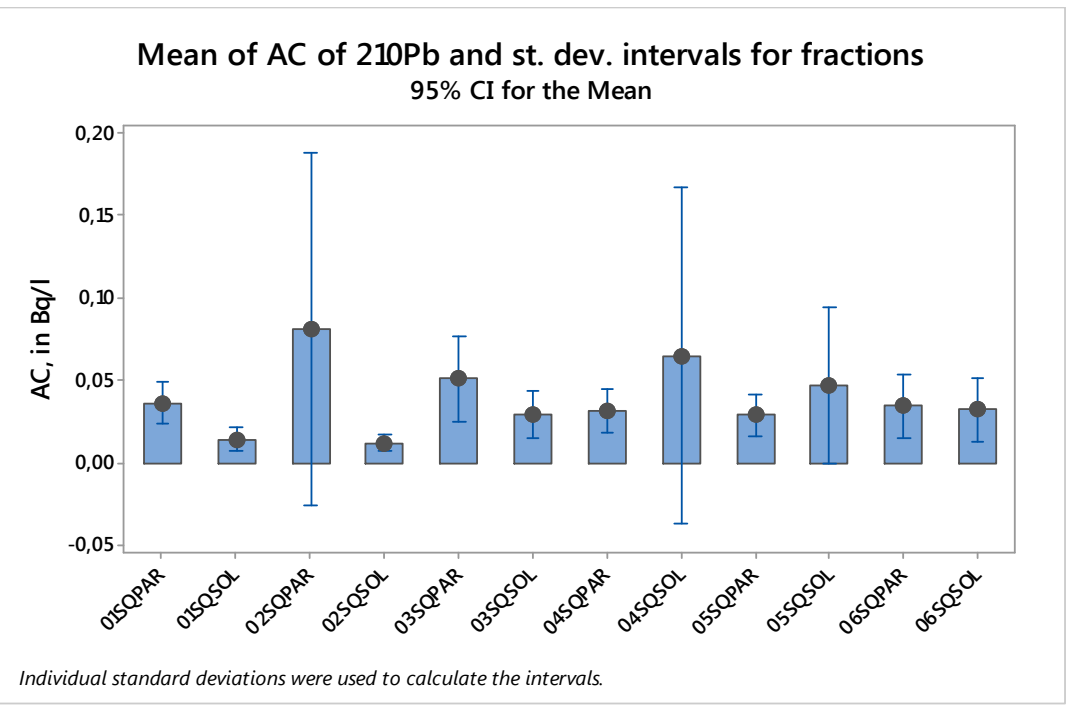

Fig. 2. Mean and intervals (st.dev.) for $A C$ of ${ }^{210} \mathrm{~Pb}$ in soluble (SOL) and particulate (PAR) fractions in surface water of Santa Quitéria region 


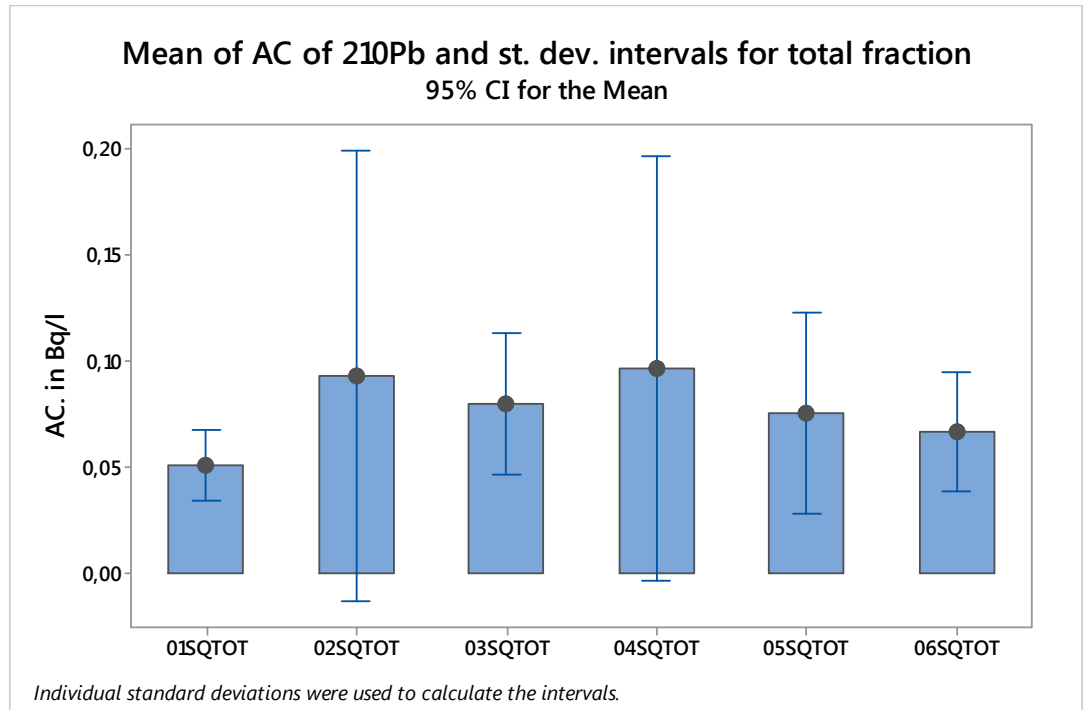

Fig. 3. Mean and intervals (st.dev.) for $A C$ of ${ }^{210} \mathrm{~Pb}$ in total fractions (TOT) in surface water of Santa Quitéria region

Fisher's test identified different groups, (Table 3) which were ranked according to the activity concentrations. The highest activity concentrations belong to group $\mathrm{G} 1$ that includes the particulate fractions of points $03 S Q, 01 S Q$, 04SQ and 02SQ. The intermediate group, G2, includes the particulate fractions of points $06 \mathrm{SQ}$ and $05 S Q$ and the soluble fractions of points 05SQ, 03SQ and 06SQ. The group associated with the lowest $A C, G 3$, includes the soluble fractions of point 01SQ, 02SQ and 04SQ. In summary, groups can be organized in function of decreasing activity concentrations as in Table 3.

The $Z$ test showed differences between the particulate and soluble fractions, pointing to the particulate fraction as the one with highest AC. Analyzing the total fraction, no differences between the points could be observed. When grouping the data by point and fraction, the ANOVA presented differences between the analyzed data, a fact corroborated by the Fisher's test, which grouped the particulate fractions of the points in groups of higher $A C$ than the soluble fractions (Table 3).

\subsection{Multivariate Statistical Analysis}

\subsubsection{Principal component analysis}

The principal component analysis showed a clear distinction between the soluble and particulate fractions, as can be seen in Fig. 4. This grouping showed that there is a difference in behavior between both kinds of fraction, confirming the ranking proposed by the Fisher's test and reinforcing the identity suggested by the $Z$ test.

Table 3. Fisher's test for mean ordination

\begin{tabular}{|c|c|c|c|c|c|c|c|c|c|c|c|c|}
\hline \multicolumn{13}{|c|}{ Point and fraction under same line are considered same AC } \\
\hline Fraction & \multicolumn{6}{|c|}{ Particulate } & \multicolumn{6}{|c|}{ Soluble } \\
\hline Point & 03SQ & 01SQ & 04SQ & 02SQ & 06SQ & 05SQ & 05SQ & 03SQ & 06SQ & 01SQ & 02SQ & 04SQ \\
\hline $\begin{array}{l}\text { Mean } \\
\left(\mathrm{Bq} \cdot \mathrm{I}^{-1}\right)\end{array}$ & 0.044 & 0.035 & 0.033 & 0.032 & 0.030 & 0.029 & 0.029 & 0.020 & 0.018 & 0.012 & 0.011 & 0.009 \\
\hline \multicolumn{13}{|l|}{ Tukeytest } \\
\hline & \multicolumn{4}{|c|}{ G1 } & \multicolumn{5}{|c|}{ G2 } & \multicolumn{3}{|c|}{ G3 } \\
\hline & \multicolumn{12}{|c|}{$\begin{array}{c}\text { Grouping } \\
\mathrm{G} 1>\mathrm{G} 2>\mathrm{G} 3\end{array}$} \\
\hline
\end{tabular}




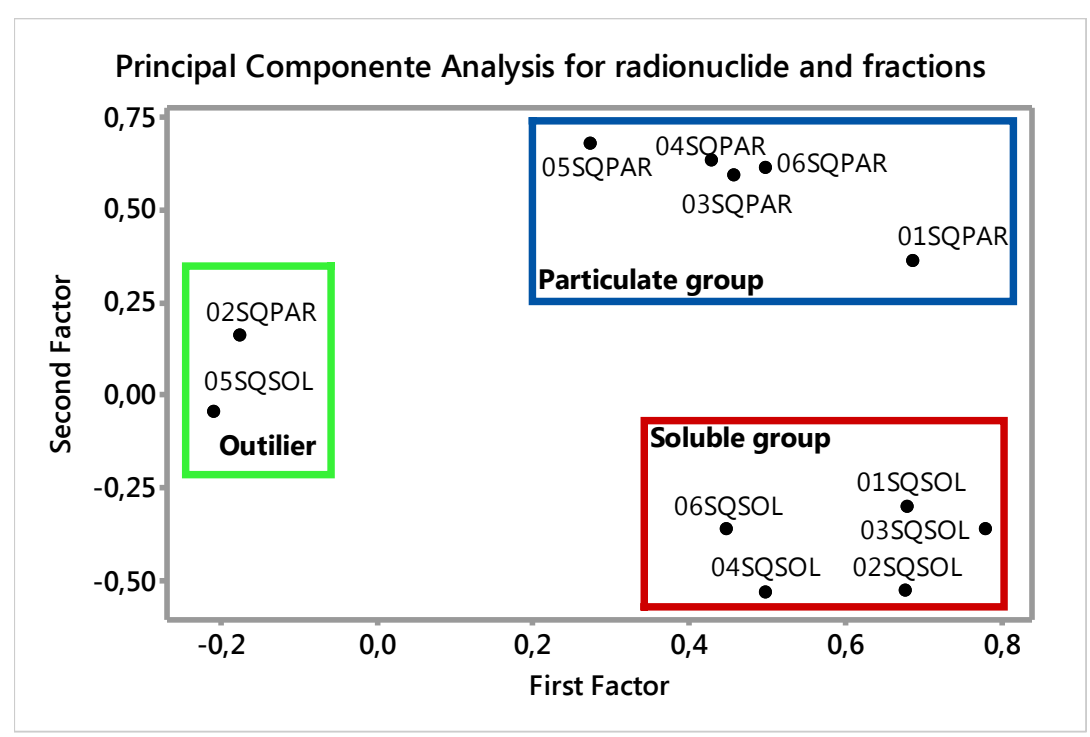

Fig. 4. Principal component analysis of data organized by point and fraction, demonstrating the separation between the soluble and particulate fraction

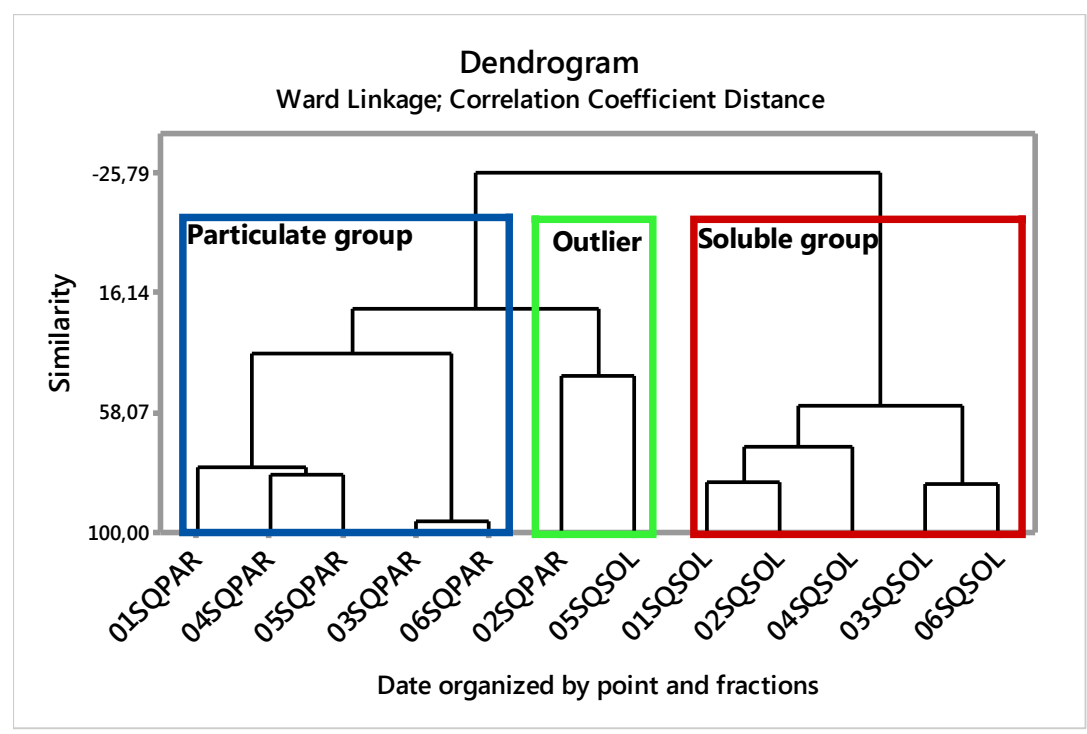

Fig. 5. Dendogram of the data organized by point and fraction, demonstrating the separation between the soluble and particulate fraction

\subsubsection{Cluster analysis}

Cluster analysis reinforced the assessment made by PCA and Fisher's tests, refuting once more the $\mathrm{Z}$ test conclusion. Thus, different behaviors are observed between the soluble and particulate fractions (PCA and Cluster) with the particulate fractions showing higher activity concentrations than the soluble fractions (Fisher).

The approach used in this study showed the importance of combining univariate and multivariate analyses for a better understanding of the behavior of radionuclides in the fractions. Indeed, the general assessment of fractions data carried out with the $Z$ test (univariate) showed different behavior between fractions. Analyzing the total fraction by ANOVA, no difference was observed between the points. On the opposite, when ANOVA is used in the data organized by points and fractions, there is evidence of difference between the samples. This last evaluation was also shown by the Fisher's test that organized the data grouping them according 
to their concentrations. At this stage, the analysis showed that the particulate fraction displayed higher levels of activity, as already detected by the $Z$ test.

In his turn, the multivariate analysis confirmed the assessment of the Fisher's test, and withstood the $Z$ test conclusion. In both analyzes (PCA and cluster) soluble fractions of collecting points were grouped and the particulate fractions put together in another group.

\section{CONCLUSION}

The assessment has shown that there are differences in the activity concentrations of ${ }^{210} \mathrm{~Pb}$ between the soluble and particulate phases of water samples collected in the region of the Santa Quitéria phosphate deposit. From all this, it can be stated that the radioecology of ${ }^{210} \mathrm{~Pb}$ in sampled area is complex, with spatial difference between the points and distribution difference between the fractions, with the particulate fraction showing higher $\mathrm{AC}$ than the soluble one.

An increase of sampling must be considered as a tool to increase the reliability both of the statistics and conclusions. A next step to be assessed is the analysis of the differences between the fractions at the collecting points. Another important aspect to be looked at is the geographic variation, comparing the same fractions (soluble or particulate) between the points.

In terms of public health, the World Health Organization (WHO) uses an 'individual dose criterion' (IDC) of $0.1 \mathrm{mSv}$ for one year's consumption of drinking water [1] as the recommended limit of ingestion of radionuclides from water. This organization develops dosimetric models that estimate the concentration of activity that generates this dose for different radionuclides. In the case of ${ }^{210} \mathrm{~Pb}$ this value is $0.1 \mathrm{~Bq} \cdot \mathrm{I}^{-1}$ [20]. Considering a linear relationship between ingestion of water and received dose and that the sum of the means of the soluble and particulate fractions is 0.05 $\mathrm{Bq} \cdot{ }^{-1}$, it results that the average dose rate resulting from the intake of ${ }^{210} \mathrm{~Pb}$ in water is half of the IDC value indicated by WHO.

In specific cases, this value may be higher than the IDC, as observed for point $02 S Q$, where the sum of the maximum values of $A C$ in the soluble and particulate fractions returns an estimated value of $A C$ of $1.35 \mathrm{~Bq} \cdot \mathrm{I}^{-1}$, that is 13 times the limit derived of 0.1 . But on the whole, the values are considered within the values indicated by the $\mathrm{WHO}$, and the waters may thus be considered as potable from a radiological point of view.

\section{DISCLAIMER}

"Some part of this manuscript was previously presented and published in the following conference.

Conference name: $3^{\text {rd }}$ International Conference on $\mathrm{Po}$ and Radioactive $\mathrm{Pb}$ Isotopes (INCO Po-Pb 2015)

Dates: October 11th-14th 2015

Location: Pine Bay Holiday Resort Hotel, Kusadasi Turkey

Web Link of the proceeding: "https://www.researchgate.net/publication/28391 0232 LEAD-

210 ASSESSMENT IN SOLUBLE AND PART ICULATE FRACTIONS OF SURFACE WATE R FROM A HIGHT BACKGROUND REGION IN BRAZIL"

\section{COMPETING INTERESTS}

Authors have declared that no competing interests exist.

\section{REFERENCES}

1. International Atomic Energy Agency. $1^{\text {st }}$ ed. Radiation protection and management of norm residues in the phosphate industry. Vienna: IAEA; 2013.

2. International Atomic Energy Agency. $1^{\text {st }}$ ed. Radiation protection and norm residue management in the titanium dioxide and related industries. Vienna: IAEA; 2012.

3. International Atomic Energy Agency. $1^{\text {st }}$ ed. Radiation protection and norm residue management in the production of rare earths from thorium containing minerals. Vienna: IAEA; 2011.

4. International Atomic Energy Agency. $1^{\text {st }}$ ed. Radiation protection and norm residue management in the zircon and zirconia industries. Vienna: IAEA; 2007.

5. Garcia MA. Caracterização radioquímica e impacto radiológico Ambiental no processamento da casiterita para a produção de estanho e chumbo metálico. M. Sc Dissertation, São Paulo, SP, Br: IPEN/USP; 2009.

6. Cipriani, M. Mitigação dos impactos sociais e ambientais decorrentes do fechamento definitivo de minas de urânio, Ph. D. 
Thesis, Campinas, SP, BR: Unicamp; 2002.

7. Pereira WS, Kelecom A, Espindola CB, Silva $A X$. Urânio em material biológico i: urânio na Bahia, Brasil, in: X Congreso Regional Latinoamericano IRPA de Protección y Seguridad Radiológica, Buenos Aires, AR; 2015.

8. Silva JR. Caracterização Hidrogeológica da Jazida de. Master degree's dissertation. Ceará: Universidade Federal do Ceará; 2003.

9. Pereira WS, Kelecom A, Pereira JR. Analysis of radium isotopes in surface waters nearby a phosphate mining with NORM at Santa Quitéria, Brazil. Journal of Environmental Protection. 2014;193-199.

10. National Comission for Nuclear Energy CNEN. Requisitos de segurança e proteção radiológica para instalações mineros-industriais. Rio de Janeiro, RJ, Brasil: CNEN; 2016.

11. National Comission for Nuclear Energy CNEN. Standart CNEN -NN-3.01 Diretrizes básicas de proteção radiologica. Rio de Janeiro, RJ, Brasil: CNEN; 2014.

12. National Comission for Nuclear Energy CNEN. Standart Posição Regulatória CNEN -NN-3.01/008:2011 Programa de Monitoração radiológico ambiental. Rio de Janeiro, RJ, Brasil: CNEN; 2011.
13. National Comission for Nuclear Energy. Standart Posição Regulatoria CNEN-NN3,01/009:2011 Modelo para elaboração de relatórios de programa de monitoração radiológica ambiental. Rio de Janeiro, RJ, Brasil: CNEN; 2011.

14. Godoy JM, Lauria CD, Godoy ML, Cunha, RP. Development of a sequencial method for determination of 238U, 234U, 232Th, 230Th, 228Th, 228Ra, 226Ra and 210Pb in environmental samples. Journal of Radioanalytical Nuclear Chemistry. 1994; 182(1):165-169.

15. Gotelli NJ, Ellison AM. A primer of ecological statistic. $1^{\text {st }}$ ed. Sunderland: Sinauer Associates; 2004.

16. Rosner B. Fundamentals of biostatistic. Stanford: Duxbury Thonson Learning. $1^{\text {st }}$ ed.; 2000.

17. Schork MA, Remington RD. Statistic with applications to the biological and health science. Prentice: Upper Saddle River, $1^{\text {st }}$ ed.; 2000.

18. Valentin JL. Ecologia númerica. Uma introdução a análise multivariada de dados ecológicos. Rio de janeiro: Interciência, $1^{\text {st }}$ ed.; 2000.

19. Ferreira DF. Estatística multivariada. Lavras: UFLA, $1^{\text {st }}$ ed.; 2008.

20. World Health Organization, Guidelines for Drinking-water Quality-4 $4^{\text {th }}$ Ed., WHO, Geneva, $1^{\text {st }}$ ed.; 2011.

(c) 2017 Pereira et al.; This is an Open Access article distributed under the terms of the Creative Commons Attribution License (http://creativecommons.org/licenses/by/4.0), which permits unrestricted use, distribution, and reproduction in any medium, provided the original work is properly cited.

Peer-review history:

The peer review history for this paper can be accessed here: http://sciencedomain.org/review-history/19243 